\author{
Preventive Care in Nursing and Midwifery Journal \\ $2020 ; 10(3): 1-10$
}

\title{
A Comparative Study of Health-Promoting Lifestyle and Quality of Life among Nurses and High School Teachers in Zanjan, Iran in 2018
}

\author{
Nasrin Jafari Varjoshani ${ }^{1}{ }^{\mathbb{D}}, \underline{\text { Azar Avazeh }}^{2 *}{ }^{*}$, Samaneh Alizadeh ${ }^{3}{ }^{\mathbb{E}}$, Koorosh Kamali ${ }^{4}$ \\ ${ }^{1} \mathrm{Ph} . \mathrm{D}$, Assistant Professor of Nursing Department of Community Health Nursing, School of Nursing and midwifery Zanjan University of Medical \\ Sciences, Zanjan, Iran \\ ${ }^{* 2}$ Instructor of Medical Surgical Nursing Department of Operating Room and Anesthesiology, School of Nursing and Midwifery Zanjan University of \\ Medical Sciences, Zanjan, Iran \\ ${ }^{3}$ Master' s Student, Medical Surgical Nursing Department, School of Nursing and Midwifery, Zanjan University of Medical Sciences, Zanjan, Iran \\ ${ }^{4}$ Ph.DAssociate Professor of Epidemiology Department of Public Health, School of Public Health Social Determinants of Health Research Center \\ Zanjan University of Medical Sciences, Zanjan, Iran
}

*Corresponding Author Address: Zanjan university of medical sciences \& health, Nursing and Midwifery faculty, Mahdavi st, Zanjan, Iran

Tel: 0098-9127433973

Email: nurse@zums.ac.ir

Received: 3 Oct $2020 \quad$ Accepted: 14 Dec 2020

\begin{abstract}
Background: A health-promoting lifestyle (HPL) can affect a person's quality of life (QOL) and prevent many diseases.

Objectives: The QOL and HPL of teachers and nurses are of great importance because of their influence on the community health and education of the new generation. The present study aimed to determine and compare the HPL and QOL of nurses and teachers in Zanjan, Iran in 2018.

Methods: This descriptive, comparative, cross-sectional study was performed on 395 teachers of governmental schools, who were selected by cluster sampling, and 182 nurses, who were selected by census sampling. Data were collected using a demographic questionnaire, health-promoting lifestyle profile (HPLP II) questionnaire, and 36-item short-form health survey (SF-36) questionnaire. Data analysis was conducted in SPSS version 16 by measuring descriptive statistics (absolute and relative frequency, mean, and standard deviation) and inferential statistics (Kolmogorov-Smirnov test, Levene's test, and independent t-test).

Results: The results showed that most of the teachers were male $(62.5 \%)$ and married $(63.8 \%)$ with a bachelor's degree $(70.1 \%)$, while the majority of nurses were female $(83 \%)$ and married $(87.4 \%)$ with a bachelor's degree $(100 \%)$. Based on the findings, the HPL of nurses and teachers was rated as moderate (40.5\% and $48.1 \%$, respectively). Also, the QOL of nurses and teachers was at a moderate level (44.6\% and $52.4 \%$, respectively). Finally, the mean QOL and HPL were lower in nurses as compared to teachers $(\mathrm{P}<0.01)$.

Conclusion: The present results revealed that having knowledge is not necessarily associated with good performance. The QOL and HPL were moderate in both teachers and nurses, even nurses had a lower QOL and HPL than teachers. Overall, awareness of the importance of healthy behaviors does not always lead to improved self-care. Therefore, it is suggested to pay more attention to the improvement of occupational conditions, besides QOL and HPL of these two groups, especially nurses.
\end{abstract}

Keywords: health-promoting lifestyle; quality of life; nurse; teacher

\section{Introduction}

According to a report by the World Health

Organization (WHO), $60 \%$ of mortality worldwide and $80 \%$ of mortality in developing countries are caused by unhealthy lifestyles. The mortality rate is projected to increase to $75 \%$ by 
2030 worldwide. One of the goals set by the WHO is to promote healthy lifestyles by 2020 [1]. Lifestyle includes routine daily activities of individuals in their lives. Health-promoting behaviors are considered as an integral part of lifestyle, influencing a person's health [2]. Walker defines a health-promoting lifestyle (HPL) as a multi-dimensional aspect of the individual's perceptions and self-motivated behaviors, contributing to the maintenance of health and selfefficacy [3].

Health-promoting behaviors and healthy lifestyles are highly influential in maintaining health [4]. Also, HPL has a significant effect on the quality of life (QOL) of individuals [5] and is the most effective approach to improve health and QOL [2]. According to the WHO's definition, QOL is a subjective phenomenon, associated with the person's understanding of different aspects of their lives [6]. QOL promotes health, happiness, and in general, a healthy lifestyle in people [7]. On the other hand, lack of attention to QOL can lead to hopelessness, loss of job motivation, and reduced social, economic, and cultural activities, while affecting the economic and social development of a country in a larger context $[7,8]$. Previous studies have reported the reduced QOL and lifestyle changes of different groups in the community [9-11]. Among different groups in the community, the QOL and lifestyle of teachers and nurses are especially important, considering their role in educating the new generation and the community's health, respectively. Evidence shows that a poor sense of wellbeing in nurses not only compromises their health, but also affects the quality of nursing services and community health [12]. Therefore, studying the nurses' lifestyle and QOL is one of the most important issues in the community, as it can affect the quality of care $[12,13]$.

Besides nurses, teachers are also important members of the community because of their key role in public education and their impact on students [14]. Among high school teachers, secondary school teachers are particularly important because of their contact with the adolescent population in the community. By stabilizing the adolescents' behaviors, teachers can encourage a sense of responsibility among students for their health and promote a healthy lifestyle throughout adolescence [15]. However, the results of most studies suggest that the QOL and HPL of teachers and nurses are not appropriate in different communities [4,16-17]. In this regard, Pirzadeh and Sharifi-Rad concluded that a large percentage of studied teachers had a moderately favorable lifestyle in terms of healthy nutrition, physical activity, and stress management [4]. Pereira et al. also showed that more experienced teachers had a lower QOL in terms of physical performance and social relationships. Also, teachers with longer working hours per week and those teaching in public schools had a lower QOL [18]. Similarly, Marzooghi et al. reported a lower QOL among teachers of selected high schools in Bushehr, Iran [19].

Regarding the QOL and HPL of nurses, similar results have been reported in different studies. Phiri et al. found that nurses often did not have a favorable lifestyle and were overweight [13]. Also, according to the results of a study by Kaldi, nurses face numerous challenges in their daily life, which negatively affect their QOL [10]. Moreover, Feyzi et al. reported the poor QOL of nurses [20]. Overall, by improving the lifestyle knowledge of nurses and teachers, who influence the health of the community, authorities can create more favorable conditions for them. Therefore, the present study aimed to compare the HPL and QOL of nurses and high school teachers in Zanjan, Iran in 2018.

\section{Methods}

This descriptive, comparative, cross-sectional study was conducted on all teachers working in Zanjan high schools and all nurses working in the general wards of university hospitals in Zanjan, Iran. The nurses were selected by census sampling. Questionnaires were distributed among 200 nurses during one month. Out of 200 distributed questionnaires, 182 were completed. The following formula was used to determine the sample size of teachers $(n=384)$ :

$n=\frac{z^{2} \times p(1-p)}{d^{2}}$

Considering the ratio of high schools in two districts of Zanjan, clusters of 17 and 25 high schools were selected in this study. Given the likelihood of sample attrition, a total of 420 questionnaires were distributed among teachers with at least one year of work experience, and 
they were collected three days later. Finally, 395 completed questionnaires were collected. The data collection tools in this study included four questionnaires: (1) nurses' demographic questionnaire; (2) teachers' demographic questionnaire; (3) health-promoting lifestyle profile (HPLP II) questionnaire; and (4) 36-item short-form health survey (SF-36) questionnaire. The HPLP II questionnaire, designed by Walker et al. [4], consists of 52 items with six dimensions of health responsibility, physical activity, nutrition, spiritual growth, interpersonal relationships, and stress management. The items are rated on a four-point Likert scale ("never", "sometimes", "often", and "routinely") and numerically ranked from 1 to 4 (1="never" and 4="routinely"). In this study, the mean scores of HPL variables were calculated on a scale of 0 to 100 so that the difference in the mean values could be easily read and interpreted; the higher the scores are, the more desirable HPL behaviors will be. The validity and reliability of this questionnaire were confirmed by Mohammadi Zeidi and Pakpour [21].

The SF-36 questionnaire is one of the most wellknown public tools for assessing health-related QOL. This tool has been translated into many languages. It includes 36 questions, measuring eight dimensions of physical functioning, physical limitation in role performance, physical pain, general health, psychological limitation in role performance, vitality, mental health and social performance. In this questionnaire, a general question determines changes in the individual's general health status over one year. The dimensions of SF-36 questionnaire, along with the questions, have a ranking scale.Some questions were re-coded in order for all scales found one direction. The mean QOL variables were calculated on a scale of 0 to 100.0 reports the worst and 100 best conditions on the scale. The validity and reliability of this questionnaire were confirmed in studies by Montazeri et al. and Ansari [22,23].

In the present study, the face validity of HPLP II and SF-36 questionnaires was confirmed, based on the opinions of ten nursing professors. The Cronbach's alpha coefficient was measured to determine the reliability of the questionnaires (0.91 and 0.82 for the HPLP II and SF-36 questionnaires, respectively). The ethical considerations in this study included obtaining approval from the university ethics committee (ZUMS.REC.1395.199), obtaining the necessary permissions for data collection, collecting informed consent forms, and considering the anonymity principle in completing the questionnaires.

Data were analyzed in SPSS version 16, using descriptive statistics (absolute and relative frequency, mean, and standard deviation) and inferential statistics, including KolmogorovSmirnov test (for determining the normality of data distribution), Levene's test (for homogeneity of variance), and t-test (for determining the mean differences between independent groups). P-value less than 0.05 was considered statistically significant.

\section{Results}

In this study, the majority of teachers were male $(62.5 \%)$ and married $(63.8 \%)$ with a bachelor's degree $(70.1 \%)$. On the other hand, the majority of nurses were female (83\%) and married (87.4\%) with a bachelor's degree (100\%). Other demographic characteristics of the participants are listed in Table 1. 
Table 1: The demographic characteristics of teachers and nurses

\begin{tabular}{llcccc}
\hline \multirow{2}{*}{ Variables } & \multicolumn{2}{c}{ Teachers } & \multicolumn{2}{c}{ Nurses } \\
\cline { 3 - 6 } Gender & Male & Number & Percentage & Number & Percentage \\
& Female & 148 & 37.5 & 151 & 83 \\
& Total & 247 & 62.5 & 31 & 17 \\
& $18-28$ & 395 & 100 & 182 & 100 \\
\hline \multirow{4}{*}{ Age (years) } & $29-38$ & 43 & 10.9 & 20 & 11 \\
& $39-48$ & 190 & 48.1 & 81 & 44.5 \\
& $49-58$ & 152 & 38.5 & 76 & 41.8 \\
& $59-68$ & 8 & 0.5 & 1 & 0.5 \\
Marital status & Single & 109 & 27.6 & 23 & 12.6 \\
& Married & 252 & 63.8 & 159 & 87.4 \\
& Widow & 34 & 8.6 & 0 & 0 \\
\hline \multirow{3}{*}{ Educational } & Associate degree & 66 & 16.7 & 32 & 17.6 \\
level & Bachelor's degree & 277 & 70.1 & 150 & 82.4 \\
& Master's degree & 51 & 12.9 & 0 & 0 \\
\hline \multirow{2}{*}{ Average } & PhD & 1 & 0.3 & 0 & 0 \\
monthly income & (1.5 million & 7 & 1.8 & 28 & 15.4 \\
(Toman) & $1.5-2.5$ million & 135 & 34.2 & 6 & 3.3 \\
\hline
\end{tabular}

It was found that the HPL of teachers and nurses was moderately good. Among nurses, interpersonal relationships had the highest score, while spiritual growth had the lowest average score. Among teachers, health responsibility and nutrition had the highest and lowest scores, respectively. The results showed that the mean
HPL of teachers was higher than nurses, and the difference was statistically significant. Also, comparison of all dimensions of HPL showed that the mean scores of all dimensions, except for interpersonal relationships, were higher among teachers than nurses, and the difference was statistically significant $(\mathrm{P}<0.05)($ Table 2$)$. 
Table 2: Comparison of differences in the mean scores of health-promoting lifestyle (HPL) dimensions in teachers and nurses

\begin{tabular}{|c|c|c|c|c|c|c|c|c|c|c|}
\hline \multirow{3}{*}{ Dimensions } & \multicolumn{3}{|c|}{$\begin{array}{l}\text { Levene's test for homogeneity } \\
\text { of variance }\end{array}$} & \multicolumn{7}{|c|}{ t-test } \\
\hline & & \multirow[b]{2}{*}{$\mathbf{F}$} & \multirow[b]{2}{*}{$\mathbf{P}$} & \multirow[b]{2}{*}{$\mathbf{t}$} & \multirow{2}{*}{$\begin{array}{l}\text { Degree } \\
\text { of } \\
\text { freedom }\end{array}$} & \multirow[b]{2}{*}{$\mathbf{P}$} & \multirow{2}{*}{$\begin{array}{l}\text { Average } \\
\text { difference }\end{array}$} & \multirow{2}{*}{$\begin{array}{c}\begin{array}{c}\text { Std. error } \\
\text { of } \\
\text { difference }\end{array} \\
\end{array}$} & \multicolumn{2}{|c|}{ Mean } \\
\hline & & & & & & & & & Teachers & Nurses \\
\hline \multirow{2}{*}{$\begin{array}{l}\text { Spiritual } \\
\text { growth }\end{array}$} & $\begin{array}{c}\text { Assumption of } \\
\text { homogeneity of } \\
\text { variance }\end{array}$ & 5.22 & 0.02 & 13.72 & 575 & 0.00 & 0.49 & 0.04 & \multirow{2}{*}{49.8} & \multirow{2}{*}{37.5} \\
\hline & $\begin{array}{c}\text { Assumption of } \\
\text { heterogeneity } \\
\text { of variance }\end{array}$ & & & 12.92 & 305.8 & 0.00 & 0.49 & 0.04 & & \\
\hline \multirow{2}{*}{$\begin{array}{c}\text { Health } \\
\text { responsibility }\end{array}$} & $\begin{array}{c}\text { Assumption of } \\
\text { homogeneity of } \\
\text { variance }\end{array}$ & 3.18 & 0.08 & 12.92 & 575 & 0.00 & 0.44 & 0.03 & \multirow{2}{*}{50.4} & \multirow{2}{*}{39.03} \\
\hline & $\begin{array}{l}\text { Assumption of } \\
\text { heterogeneity } \\
\text { of variance }\end{array}$ & & & 14.24 & 450.53 & 0.00 & 0.44 & 0.03 & & \\
\hline \multirow{2}{*}{ Nutrition } & $\begin{array}{c}\text { Assumption of } \\
\text { homogeneity of } \\
\text { variance } \\
\end{array}$ & 3.90 & 0.05 & 5.25 & 575 & 0.00 & 0.20 & 0.04 & \multirow{2}{*}{45} & \multirow{2}{*}{40} \\
\hline & $\begin{array}{c}\text { Assumption of } \\
\text { heterogeneity } \\
\text { of variance }\end{array}$ & & & 5.23 & 349.22 & 0.00 & 0.20 & 0.04 & & \\
\hline \multirow{2}{*}{$\begin{array}{l}\text { Physical } \\
\text { activity }\end{array}$} & $\begin{array}{c}\text { Assumption of } \\
\text { homogeneity of } \\
\text { variance }\end{array}$ & 7.98 & 0.01 & 6.14 & 575 & 0.00 & 0.32 & 0.05 & \multirow{2}{*}{50.2} & \multirow{2}{*}{42.1} \\
\hline & $\begin{array}{c}\text { Assumption of } \\
\text { heterogeneity } \\
\text { of variance }\end{array}$ & & & 7.00 & 488.96 & 0.00 & 0.32 & 0.05 & & \\
\hline \multirow{2}{*}{$\begin{array}{c}\text { Stress } \\
\text { management }\end{array}$} & $\begin{array}{c}\text { Assumption of } \\
\text { homogeneity of } \\
\text { variance } \\
\end{array}$ & 0.06 & 0.85 & 6.17 & 575 & 0.00 & 0.25 & 0.04 & \multirow{2}{*}{45.5} & \multirow{2}{*}{39.3} \\
\hline & $\begin{array}{c}\text { Assumption of } \\
\text { heterogeneity } \\
\text { of variance }\end{array}$ & & & 6.31 & 373.01 & 0.00 & 0.25 & 0.04 & & \\
\hline \multirow{2}{*}{$\begin{array}{l}\text { Interpersonal } \\
\text { relationships }\end{array}$} & $\begin{array}{c}\text { Assumption of } \\
\text { homogeneity of } \\
\text { variance }\end{array}$ & 4.58 & 0.03 & -0.23 & 575 & 0.82 & -0.01 & 0.05 & \multirow{2}{*}{45.6} & \multirow{2}{*}{45.9} \\
\hline & $\begin{array}{c}\text { Assumption of } \\
\text { heterogeneity } \\
\text { of variance }\end{array}$ & & & -0.25 & 420.18 & 0.82 & -0.01 & 0.04 & & \\
\hline \multirow{2}{*}{ HPL } & $\begin{array}{c}\text { Assumption of } \\
\text { homogeneity of } \\
\text { variance } \\
\end{array}$ & 435 & $0 \Omega 4$ & 9.01 & 575 & 0.00 & 0.28 & 0.03 & \multirow{2}{*}{48.1} & \multirow{2}{*}{40.5} \\
\hline & $\begin{array}{c}\text { Assumption of } \\
\text { heterogeneity } \\
\text { of variance }\end{array}$ & 4.55 & 0.04 & 10.34 & 496.02 & 0.00 & 0.28 & 0.03 & & \\
\hline
\end{tabular}

In the present study, the QOL of teachers and nurses was at a moderate level. The mean QOL score of teachers was higher than that of nurses, and the difference was statistically significant $(\mathrm{P}=0.00)$. Also, significant differences were found between these groups in terms of four dimensions of physical functioning, no physical limitation in role performance, mental health, and vitality.
However, there were no significant differences regarding other dimensions. The dimension of lack of physical pain had the highest score in both groups of teachers and nurses. The lowest mean score was related to vitality among teachers and no psychological limitation in role performance in nurses (Table 3 ). 
A Comparative Study of Health-Promoting Lifestyle ....

Table 3: Comparison of the mean difference in the quality of life $(Q O L)$ of teachers and nurses

\begin{tabular}{|c|c|c|c|c|c|c|c|c|c|c|}
\hline \multirow{3}{*}{ Dimensions } & \multicolumn{3}{|c|}{$\begin{array}{c}\text { Levene's test for } \\
\text { homogeneity of variance }\end{array}$} & \multicolumn{7}{|c|}{ t-test } \\
\hline & & \multirow{2}{*}{$\mathbf{F}$} & \multirow{2}{*}{$\mathbf{P}$} & \multirow{2}{*}{$\mathbf{t}$} & \multirow{2}{*}{$\begin{array}{c}\text { Degree } \\
\text { of } \\
\text { freedom }\end{array}$} & \multirow{2}{*}{$\mathbf{P}$} & \multirow{2}{*}{$\begin{array}{l}\text { Averages } \\
\text { difference }\end{array}$} & \multirow{2}{*}{ SD } & \multicolumn{2}{|c|}{ Mean } \\
\hline & & & & & & & & & Teachers & Nurses \\
\hline \multirow{2}{*}{$\begin{array}{c}\text { Physical } \\
\text { functioning }\end{array}$} & $\begin{array}{l}\text { Assumption } \\
\text { of the } \\
\text { homogeneity } \\
\text { of variance }\end{array}$ & 7.3 & 0.00 & 4.03 & 575.0 & 0.00 & 8.50 & 2.11 & \multirow{2}{*}{54.6} & \multirow{2}{*}{46} \\
\hline & $\begin{array}{l}\text { Assumption } \\
\text { of the } \\
\text { heterogeneity } \\
\text { of variance }\end{array}$ & & & 3.90 & 325.3 & 0.00 & 8.50 & 2.18 & & \\
\hline \multirow{2}{*}{$\begin{array}{l}\text { No physical } \\
\text { limitation in } \\
\text { role } \\
\text { performance }\end{array}$} & $\begin{array}{l}\text { Assumption } \\
\text { of the } \\
\text { homogeneity } \\
\text { of variance }\end{array}$ & 0.19 & 0.00 & -0.46 & 575.0 & 0.65 & -0.83 & 1.81 & \multirow{2}{*}{57.1} & \multirow{2}{*}{57.9} \\
\hline & $\begin{array}{l}\text { Assumption } \\
\text { of the } \\
\text { heterogeneity } \\
\text { of variance }\end{array}$ & & & -0.46 & 345.0 & 0.65 & -0.83 & 1.82 & & \\
\hline \multirow{2}{*}{$\begin{array}{c}\text { Lack of } \\
\text { physical pain }\end{array}$} & $\begin{array}{l}\text { Assumption } \\
\text { of the } \\
\text { homogeneity } \\
\text { of variance }\end{array}$ & 0.00 & 0.99 & 0.19 & 575.0 & 0.85 & 0.15 & 0.80 & \multirow{2}{*}{65.6} & \multirow{2}{*}{65.4} \\
\hline & $\begin{array}{l}\text { Assumption } \\
\text { of the } \\
\text { heterogeneity } \\
\text { of variance }\end{array}$ & & & 0.19 & 350.0 & 0.85 & 0.15 & 0.80 & & \\
\hline \multirow{2}{*}{$\begin{array}{l}\text { General } \\
\text { health }\end{array}$} & $\begin{array}{l}\text { Assumption } \\
\text { of the } \\
\text { homogeneity } \\
\text { of variance }\end{array}$ & 0.00 & 0.95 & 0.00 & 575.0 & 1.00 & 0.00 & 0.42 & \multirow{2}{*}{53} & \multirow{2}{*}{53} \\
\hline & $\begin{array}{l}\text { Assumption } \\
\text { of the } \\
\text { heterogeneity } \\
\text { of variance }\end{array}$ & & & 0.00 & 349.6 & 1.00 & 0.00 & 0.42 & & \\
\hline \multirow{2}{*}{$\begin{array}{c}\text { No } \\
\text { psychological } \\
\text { limitation in } \\
\text { role } \\
\text { performance }\end{array}$} & $\begin{array}{l}\text { Assumption } \\
\text { of the } \\
\text { homogeneity } \\
\text { of variance }\end{array}$ & 282.34 & 0.00 & 13.68 & 575.0 & 0.00 & 36.58 & 2.67 & \multirow{2}{*}{64} & \multirow{2}{*}{27.4} \\
\hline & $\begin{array}{l}\text { Assumption } \\
\text { of the } \\
\text { heterogeneity } \\
\text { of variance }\end{array}$ & & & 15.55 & 485.5 & 0.00 & 36.58 & 2.35 & & \\
\hline \multirow{2}{*}{ Vitality } & $\begin{array}{l}\text { Assumption } \\
\text { of the } \\
\text { homogeneity } \\
\text { of variance }\end{array}$ & 8.39 & 0.00 & 12.05 & 575.0 & 0.00 & 9.77 & 0.81 & \multirow{2}{*}{39.8} & \multirow{2}{*}{30.1} \\
\hline & $\begin{array}{l}\text { Assumption } \\
\text { of the } \\
\text { heterogeneity } \\
\text { of variance }\end{array}$ & & & 10.65 & 267.7 & 0.00 & 9.77 & 0.92 & & \\
\hline \multirow{2}{*}{$\begin{array}{l}\text { Mental } \\
\text { health }\end{array}$} & $\begin{array}{l}\text { Assumption } \\
\text { of the } \\
\text { homogeneity } \\
\text { of variance }\end{array}$ & 1.07 & 0.30 & 10.59 & 575.0 & 0.00 & 8.46 & 0.80 & \multirow{2}{*}{42.7} & \multirow{2}{*}{34.3} \\
\hline & $\begin{array}{l}\text { Assumption } \\
\text { of the } \\
\text { heterogeneity } \\
\text { of variance }\end{array}$ & & & 10.72 & 363.1 & 0.00 & 8.46 & 0.79 & & \\
\hline
\end{tabular}




\begin{tabular}{|c|c|c|c|c|c|c|c|c|c|c|}
\hline \multirow{2}{*}{$\begin{array}{c}\text { social } \\
\text { performance }\end{array}$} & $\begin{array}{c}\text { Assumption } \\
\text { of the } \\
\text { homogeneity } \\
\text { of variance }\end{array}$ & 0.24 & 0.62 & -0.24 & 575.0 & 0.81 & -0.31 & 1.28 & \multirow{2}{*}{49.6} & \multirow{2}{*}{49.9} \\
\hline & $\begin{array}{l}\text { Assumption } \\
\text { of the } \\
\text { heterogeneity } \\
\text { of variance }\end{array}$ & & & -0.24 & 341.7 & 0.81 & -0.31 & 1.30 & & \\
\hline \multirow{2}{*}{ QOL } & $\begin{array}{l}\text { Assumption } \\
\text { of the } \\
\text { homogeneity } \\
\text { of variance }\end{array}$ & \multirow{2}{*}{0.13} & \multirow{2}{*}{0.72} & 9.43 & 575.0 & 0.00 & 7.79 & 0.83 & \multirow{2}{*}{52.4} & \multirow{2}{*}{44.6} \\
\hline & $\begin{array}{l}\text { Assumption } \\
\text { of the } \\
\text { heterogeneity } \\
\text { of variance }\end{array}$ & & & 9.31 & 341.0 & 0.00 & 7.79 & 0.84 & & \\
\hline
\end{tabular}

\section{Discussion}

In the present study, comparison of HPL between teachers and nurses showed that the mean scores of all HPL dimensions, except for interpersonal relationships, were higher in teachers than nurses, and the difference was statistically significant. According to our literature review, there are no studies comparing the HPL of teachers and nurses, which is one of the unique strengths of the present study. Although having a healthy lifestyle is an integral part of nursing education, the HPL of nurses was lower than teachers. Also, comparison of the QOL of teachers and nurses showed that the average QOL of teachers was higher than nurses, and the difference was statistically significant.

According to previous research, the poor QOL of nurses is related to the interference of their professional life with their personal life, long working hours, night shifts, irregular working hours, overtime, and overwork, all of which result in more fatigue and mental distress. In addition, nurses' observation of patients' pain and suffering, and even sometimes the death of patients, can have significant negative effects on the nurses' morale [20,23]. We also believe that the higher number of female nurses as compared to female teachers in the present study contributed to this finding, as women are generally more emotional than men. Also, since most of the studied nurses were married with children, coordination between irregular working hours and personal life was more difficult for them and affected their QOL.

The present study showed that HPL was moderate among teachers. This finding is consistent with the results of previous studies, including a study by Charkazi et al. [24]. Some studies have also shown that people refuse to adhere to HPL behaviors despite being aware of their protective role against chronic diseases. For example, Imanipour et al. showed that teachers did not adhere to preventive behaviors despite having good knowledge of the risk factors for heart disease. In this study, $67 \%$ of teachers were aware of the risk factors for heart disease, while only $27.7 \%$ had a safe and healthy diet, and only $35.6 \%$ had regular exercise [25]. On the other hand, Pirzadeh et al. found the lifestyle of most teachers to be favorable; the discrepancy between the results may be attributed to differences in the environment and the research community. It should be noted that the population of their study included the community of teachers in a single area of Isfahan, which reduces the generalizability of findings [4], whereas the present study was conducted on teachers from different regions of Zanjan, Iran.

Among HPL dimensions, the teacher's responsibility had the highest average score. In another study, the teachers' social responsibility was found to be above average [26]. These findings may be related to the nature of teacher's occupation that requires a feeling of responsibility in teachers. In general, responsible people tend to choose the teaching profession. In Zanjan, which is known as a religious city, people may be influenced by Islamic beliefs, cultural values of research field. Through school or university education and national media, people learn to be responsible, since from an Islamic point of view, humans are responsible for their own health.

Moreover, in the present study, the lowest mean score of teachers was related to nutrition, which may be related to recent advertisements against palm oil, leading some people to believe that 
animal fats are without palm so they are healthier . Also, the high cost of natural oils, such as olive and sesame oil, besides the low income of teachers, may be effective. This finding is consistent with the results of a study by Pirzadeh and Sharifi-Rad [4]. They showed that only $7.27 \%$ of teachers had healthy eating habits. Conversely, our results are not consistent with the findings of a study by Charkazi et al. [24]. which could be related to the difference in the research environments.

The present results showed that the QOL of teachers was at a moderate level, which contradicts the results of a study by Marzougi et al., which showed that the QOL of selected high school teachers was less than moderate in Bushehr, Iran [19]. This discrepancy could be due to differences in the research community, environment, cultural factors, expectations, and attitudes toward life. Moreover, in the present study, the highest mean score of QOL in teachers was related to the lack of physical pain; this finding could be related to the age range and gender of most samples (male teachers, aged 2938 years). Also, the lowest mean score of QOL was related to the dimension of vitality. Generally, one's feeling of well-being is partly dependent on income, besides the living environment. Zanjan has fewer recreational centers and urban landscapes, which might explain this finding. However, in a study by Pereira et al., teachers, especially those with more experience, had a lower QOL in terms of physical functioning and social relationships [18]; this could be related to the higher average age of the samples in Pereira' study.

Furthermore, the present results showed that the HPL of nurses was moderate, which is in line with the results of a study by Ghanbari Sartong et al. [27]. Also, our results are consistent with the results of studies from other countries. In this regard, Ross et al. found that despite the nurses' awareness of the importance of healthy behaviors, this knowledge did not necessarily lead to selfcare [28]. Also, Can et al. reported a moderately healthy lifestyle among nurses in Istanbul, Turkey [29]. In addition, the results of a study by Nahm et al. showed that $53.8 \%$ of nurses did not have a regular diet, and $72.2 \%$ did not exercise [30].

The mentioned findings can be explained by the fact that nurses have the necessary knowledge to pursue a healthy lifestyle; however, given the nature of their job (e.g., exposure to stress at work and lack of fixed work shifts), besides their lack of access to facilities, such as sports clubs, specific working hours, and lack of regular sleep time, they are unable to adopt a healthy lifestyle. In this regard, a study by Ghanbari et al. showed that nurses with work shifts had a poorer lifestyle than nurses with fixed shifts [27].

On the other hand, Mohammad Beigi et al. investigated the HPL of nurses in Qom, Iran, and found it to be slightly above average [31]. The cause of discrepancy between their findings and the present results may be differences in the demographic characteristics of the participants in the two studies. In the study by Mohammad Beigi et al., the percentage of single men and women was higher than that of the present study, which might justify the adherence to HPL in their study, as single men have more opportunities to adhere to HPL behaviors as compared to married women; also, more sports facilities are available to men. In this regard, Kalroozi et al. found that the HPL behaviors were acceptable in 400 nurses of various military hospitals [32].

In the present study, the dimension of interpersonal relationships had the highest average score among nurses. Generally, interpersonal relationships are one of the most important skills of nurses. In other words, it is essential for nurses to communicate effectively with the patients, caregivers, and colleagues and fulfill their professional responsibilities. Nurses are also taught about the importance of interpersonal communication during their education. It seems that the high mean score of this dimension is related to the importance of nursing responsibilities.

Although in the present study, the dimension of spiritual growth had a higher mean score as compared to a study by Kalroozi et al. [32], higher scores were expected considering the cultural context of the research community. Therefore, it seems that special attention must be paid to promoting the spiritual growth of nurses and exploring the causes; also, providing necessary guidance must be prioritized.

There were two limitations in this study, that is, the use of a self-report method to collect the data and lack of similar studies to compare the results. 


\section{Conclusion}

The present results showed that HPL and QOL were moderate among teachers and nurses. Therefore, it is recommended for education managers, health policymakers, and hospital authorities to facilitate the improvement of QOL and HPL among nurses and teachers. Also, identifying the obstacles to HPL and eliminating them by holding healthy lifestyle training courses and stress management counseling classes can promote a healthy lifestyle. Moreover, the present results showed the unfavorable HPL and QOL of nurses, despite their adequate knowledge. Nurses can have a healthy lifestyle if their working conditions are improved, sufficient human resources are provided, and the forced labor hours are reduced. Financial support, as well as travel and welfare programs for employees and their families, can also greatly improve the HPL and QOL of both groups.

\section{Acknowledgments}

This study was extracted from a graduate thesis of medical-surgical nursing (code: A-11-199-3) and funded by Zanjan University of Medical Sciences and Services. We greatly appreciate all the teachers and nurses participating in this study.

\section{Conflict of interest}

We declare that there is no conflict of interest regarding the publication of this paper.

\section{References}

1. Jahani Eftekhari M, Peyman N, Doosti H. The Effect of Educational Intervention based on the Self Efficacy and Health Literacy Theory on Health Promoting Lifestyles among Female Health Volunteers of Neyshabur, Iran. Health Develop J. 2017; 6(4): 302-13.[ In Persian]

2. Sousa P, Gaspar P, Fonseca H, Hendricks C, Murdaugh C. Health promoting behaviors in adolescence: validation of the Portuguese version of the Adolescent Lifestyle Profile. J Pediatr. 2015; 91(4): 358-65.

3. Walker SN, Kerr MJ, Pender NJ, Sechrist KR. A Spanish language version of the HealthPromoting Lifestyle Profile. NursRes. 1990; 39(5): 268-73.

4. Pirzadeh A, Sharifirad G. A Survey of Healthy Life Styles in Teachers in District 4 of Isfahan, Iran. J Health Syst Res. 2010; 7(6):1075-81. [In Persian]
5. Fransen HP, May AM, Beulens JWJ, et al. Association between Lifestyle Factors and Quality-Adjusted Life Years in the EPIC-NL Cohort. PLoS ONE. 2014; 9(11): e111480.

6. Geneva W. World Health Organisation: Ottawa charter for health promotion. J Health Promotion. 1986; 1: 1-4.

7. Oyama Y, Fukahori H. A literature review of factors related to hospital nurses' health-related quality of life. J Nurs Manag. 2015; 23(5): 66173.

8. Essen L, Larsson G, Öberg K, Sjödén PO. Satisfaction with care: associations with health-related quality of life and psychosocial function among Swedish patients with endocrine gastrointestinal tumours. Eur J Cancer Care. 2002; 11(2): 91-99.

9. Janjani P, Momeni K, Karami J. The Relationship between Social Security and Life Style with Life Quality and Happiness of the Women in Kermanshah. J Clin Res Paramed Sci. 2014; 3(4): 247-56. [In Persian]

10. Kaldi A, Einodin H, Mohagheghi Kamal SH, Soltani R. The Evaluation of Relationship between Health-Promoting Lifestyle and Quality of Life (Case of Study: University of Social Welfare and Rehabilitation Sciences Students in Tehran). J Iran Soc Dev Stud. 2014; 6(4): 87-96. [In Persian]

11. Arbabisarjou A, Ajdari Z, Omedi K. Relationship between health promotion life style and life quality among nursing students. World Sci J . 2013; 2: 142-7. [ In Persian]

12. Saadati M, Ghoreishi Z. Health Promoting Lifestyle in Shahed Students Tabriz University of Medical Sciences. Depiction of Health. 2016; 7(1): 27-33. [ In Persian]

13. Phiri LP, Draper K, Lambert EV, KolbeAlexander TL. Nurses' lifestyle behaviours, health priorities and barriers to living a healthy lifestyle: a qualitative descriptive study. BMC Nursing. 2014; 13: 38.

14. Ahmadnejad M, Hassani M, Sepehrian Azar F, Shojaee K. Surveying the relationship between Emotional intelligence and working life quality with job adjustment of registered and unregistered teachers in elementary school of Sardasht Pronince 2010-2011. Res Curriculum Planning. 2012; 9(5): 123-36. [In Persian]

15. Ghorbani F. Study the effect of life skills training on mental health and locus of control 
teens[dissertation]. Science Education at Islamic Azad University, Science and Research Tehran. 2016 .

16. Koshki Ansari H, Abassi M, Nourozzadeh R. Health - related Quality of Life among Nurses in Zahedan University of Medical Sciences Hospitals. J Hosp. 2016; 14(3): 47-55. [In Persian]

17. Sepahmansour M, Shahriyari Ahmadi M, Shohami N. Relationship between life quality, Job satisfaction and teachers' professional exhaustion. Edu Admin Res Quarterly. 2012; 3(11): 91-110. [In Persian]

18. Pereira EF, Teixeira CS, Andrade RD, SilvaLopes A. Elementary school teachers and their quality of life. Rev Salud Publica (Bogota). 2014;16(2): 221-31.

19. Marzooghi R, Noroozi N, Nickhoo ME. The Analysis of Work Life Quality for Exceptional Schools Teachers in Bushehr Province. Journal of Exceptional Education. 2013;4(117):5-17.

20- Feyzi v, Jafari Roodbandi A, Farahbakhsh S, Rezaei H. The Investigation of Occupational and Demographic Factors Effective on the Quality of Life of Nurses and Nurse Aides Working in Teaching Hospitals Affiliated to Kerman University of Medical Sciences in 2014. J Ergonomics. 2016; 4(3): 33-40. [In Persian] 21- Mohammadi Zeidi I, Pakpour Hajiagha A, Mohammadi Zeidi B. Reliability and Validity of Persian Version of the Health-Promoting Lifestyle Profile. J Mazandaran Univ Med Sci. 2012; 21(1): 102-13. [In Persian]

22. Montazeri A, Gashtasbi A, Vahdaninia M. The Short Form Health Survey (SF-36): translation and validation study of the Iranian version. Payesh. 2005; 5(1): 49-56. [In Persian] 23. Ansari H, Abbasi M. Health - related Quality of Life among Nurses in Zahedan University of Medical Sciences Hospitals. J Hosp. 2015; 14(3): 47-55. [In Persian]
24. Charkazi A, Koochaki GM, Shahnazi H, Ekrami Z, Bahador E. Lifestyle of teachers working in Gorgan City in 2009. J Health Syst Res. 2009; 6(3): 522-31. [In Persian]

25. Imanipour $M$, Basampour S, Haghani HR. Preventive behaviors of cardiac diseases and their relationship with knowledge of risk factors. Hayat. 2008; 14(2): 41-49. [In Persian]

26. Mohammadi A, Hanifi N, Jafari N. The organizational justice, consciousness and responsibility of the Iranian nurses" which you submitted to Nursing Ethics[dissertation]. Zanjan University of Medical Science; 2019. [In Persian]

27. Ghanbari Sartang A, Ashnagar M, Dehghan $\mathrm{H}$, Mohammadpour H. Relationship investigation burnout job with health promotion lifestyle in nurse's occupation in Ilam province hospitals in 2015. Pajoohande. 2016; 21(2): 74-79. [In Persian]

28. Ross A, Bevans M, Brooks A T, Gibbons S, Gwenyth R. Wallen G R, Nurses and HealthPromoting Behaviors. AORN J. 2017; 105(3): 267-75.

29. Can A, Ozdilli K, Erol O. Comparison of the health-promoting lifestyles of nursing and nonnursing students in Istanbul, Turkey. Nurs Health Sci. 2008; 10(4): 273-80.

30. Nahm ES, Warren J, Zhu S, An M, Brown J. Nurses' self-care behaviors related to weight and stress. Nursing Outlook J. 2012; 60( 5): 23-31.

31. Mohammad Beigi A, Anbari Z, Mohammad Salehi N, et al. Study of the relationship between self-efficacy and health promoting lifestyle and associated factors in nurses. Qom Univ Med Sci J. 2016; 10(7): 49-57. [In Persian]

32. Kalroozi F, Pishgooie SA, Taheriyan A, Khayat S, Faraz R. Health-promoting behaviours and related factors among nurses in selected military hospitals. Mil Caring Sci. 2015; 2(2): 7080. [In Persian]. 